\title{
Individualized PEEP Setting in Subjects With ARDS: A Randomized Controlled Pilot Study
}

\author{
María-Consuelo Pintado MD PhD, Raúl de Pablo MD PhD, María Trascasa, \\ José-María Milicua, Santiago Rogero, Martín Daguerre, José-Andrés Cambronero, \\ Ignacio Arribas MD PhD, and Miguel Sánchez-García MD PhD
}

\begin{abstract}
BACKGROUND: Low-tidal-volume ventilation may be associated with repetitive opening and closing of terminal airways. The use of PEEP is intended to keep the alveoli open. No method of adjusting the optimal PEEP has shown to be superior or to improve clinical outcomes. We conducted a pilot study to evaluate the effect of setting an individualized level of PEEP at the highest compliance on oxygenation, multiple-organ-dysfunction, and survival in subjects with ARDS. METHODS: Subjects with ARDS ventilated with low tidal volumes and limitation of airway pressure to $30 \mathrm{~cm} \mathrm{H}_{2} \mathrm{O}$ were randomized to either a compliance-guided PEEP group or an $\mathrm{F}_{\mathrm{IO}_{2}}$-guided group. RESULTS: Of the 159 patients with ARDS admitted during the study period, 70 met the inclusion criteria. Subjects in the compliance-guided group showed nonsignificant improvements in $\mathrm{P}_{\mathrm{aO}_{2}} / \mathrm{F}_{\mathrm{IO}_{2}}$ during the first 14 days, and in 28 -day mortality $(20.6 \%$ vs. 38.9\%, $P=.12)$. Multipleorgan-dysfunction-free days (median 6 vs $20.5 \mathrm{~d}, P=.02$ ), respiratory-failure-free days (median 7.5 vs $14.5 \mathrm{~d}, P=.03$ ), and hemodynamic-failure-free days (median 16 vs $22 \mathrm{~d}, P=.04$ ) at 28 days were significantly lower in subjects with compliance-guided setting of PEEP. CONCLUSIONS: In ARDS subjects, protective mechanical ventilation with PEEP application according to the highest compliance was associated with less organ dysfunction and a strong nonsignificant trend toward lower mortality. ClinicalTrials.gov Number NCT01119872. Key words: ARDS; mechanical ventilation; tidal volume; multiple organ dysfunction. [Respir Care 2013;58(9):1416-1423. () 2013 Daedalus Enterprises]
\end{abstract}

\section{Introduction}

ARDS is characterized by the acute onset of hypoxemia and bilateral infiltrates that are consistent with pulmonary

\footnotetext{
Dr Pintado, Dr de Pablo, Ms Trascasa, Mr Milicua, Mr Rogero, Mr Daguerre, Dr Cambronero, and Dr Sánchez-García are affiliated with the Intensive Care Unit; and Dr Arribas is affiliated with the Foundation for Biomedical Research, Hospital Universitario Príncipe de Asturias, Alcalá de Henares, Madrid, Spain.
}

Drs Pintado and de Pablo are co-first authors.

Supplementary material related to this paper is available at http:// www.rcjournal.com.

Correspondence: María-Consuelo Pintado MD PhD, Intensive Care Unit, Hospital Universitario Príncipe de Asturias, Carretera Alcalá-Meco, SN E-28805, Alcalá de Henares, Madrid, Spain. E-mail: consuelo pintado@yahoo.es.

DOI: $10.4187 /$ respcare. 02068 edema, without evidence of left heart failure. ${ }^{1}$ Mechanical ventilation is potentially lifesaving in patients with ARDS, but may cause ventilator-associated lung injury. Lungprotective ventilation strategies seek to prevent ventilatorassociated lung injury by using low tidal volume $\left(\mathrm{V}_{\mathrm{T}}\right)$ to avoid overdistention, and PEEP to prevent repetitive alveolar collapse and reopening. ${ }^{2-4}$

See the Related Editorial on Page 1552

The application of PEEP improves gas exchange and lung function. The main effect of increasing PEEP is to maintain the recruitment of alveolar units that were previously collapsed. Thus, since the $\mathrm{V}_{\mathrm{T}}$ is distributed to more alveoli, peak airway pressure is reduced and compliance is increased. ${ }^{5}$ However, the pressure needed to open and recruit some alveoli may overdistend others, which may direct blood perfusion away from these areas, thereby increasing dead space, pulmonary vascular resistance, and 
mean hydrostatic pressure, and thus increase lung damage. ${ }^{6}$ The preferred method of adjusting the PEEP is still controversial. 7,8 The amount of potentially recruitable lung tissue has best been evaluated using computed tomography, ${ }^{9}$ but this approach is usually not readily available in ICUs for routine assessment of ventilator settings.

Some have suggested that lung mechanics are a better surrogate than gas exchange for bedside assessment of lung recruitment, ${ }^{10}$ and that the PEEP should be chosen individually. ${ }^{10-12}$ In fact, several studies have shown improved survival when PEEP is set above the lower inflection point on the pressure-volume curve, the steepest portion of the curve, a sign of increase of functional residual capacity. ${ }^{12-15}$ Unfortunately, all these studies also compared low versus high $\mathrm{V}_{\mathrm{T}}$ ventilation, which hinders evaluation of the effect directly attributable to PEEP. Recently, 2 studies compared different methods of PEEP setting. One study, based on individual maximum alveolar recruitment, failed to demonstrate a reduction in mortality, although they observed significant improvements in oxygenation ${ }^{16}$ and lung function. ${ }^{17}$

We conducted an open, randomized controlled pilot study to test the hypothesis that individualized PEEP set based on highest compliance would improve oxygenation, compared to setting PEEP based on $\mathrm{F}_{\mathrm{IO}_{2}} \cdot{ }^{18}$

\section{Methods}

This study was conducted in a 14-bed mixed medicalsurgical ICU in Spain, over a time period of 60 months. The study protocol was approved by our institution's Ethics and Clinical Trials Committee, and registered at http://clinicaltrials.gov (NCT01119872). Written informed consent was required for inclusion, and obtained from the nearest relatives. No commercial entities had any role in any aspect of this study.

We screened all patients with ARDS according to the American-European consensus conference definition, ${ }^{1}$ who maintained ARDS criteria after 24 hours of mechanical ventilation, in order to confirm ARDS and exclude other causes of hypoxemia and pulmonary infiltrates, since mechanical ventilation parameters can affect oxygenation and whether the patient meets the ARDS definition. ${ }^{19}$ We excluded patients who were younger than 18 years, pregnant, or had neuromuscular disease, intracranial hypertension, head trauma, left ventricular dysfunction (on echocardiography), $>72$ hours of mechanical ventilation, or barotrauma. Patients with end-stage conditions (death expected within 90 days) were also excluded. We defined barotrauma as the presence of air outside the tracheobronchial tree, resulting from presumed alveolar rupture, and manifested as interstitial emphysema, pneumothorax, pneumomediastinum, pneumoperitoneum, or subcutaneous emphysema. ${ }^{20}$ Patients who developed barotrauma during the

\section{QUICK LOOK}

\section{Current knowledge}

Lung-protective ventilation (low tidal volume and limited plateau pressure) improves outcomes in ARDS, but the best method of selecting the PEEP is controversial, and clinical trials have had conflicting results.

\section{What this paper contributes to our knowledge}

In ARDS patients, low-tidal-volume ventilation coupled with PEEP set according to the highest pulmonary compliance was associated with more organdysfunction-free days and a trend toward lower mortality.

first 24 hours of observation prior to randomization were also excluded, because it was not feasible to measure plateau pressure. In subjects excluded after randomization, the respiratory protocol was not applied, although protective lung ventilation was maintained, and they were kept in their assigned study groups for outcome analysis.

\section{Study Design}

All patients who met ARDS criteria were ventilated during 24 hours with low $\mathrm{V}_{\mathrm{T}}(6-8 \mathrm{~mL} / \mathrm{kg}$ predicted body weight $[\mathrm{PBW}]$ ), an inspiratory plateau pressure $<30 \mathrm{~cm}$ $\mathrm{H}_{2} \mathrm{O}$, a breathing frequency of 30 breaths/min, adjusted to maintain a pH between 7.30 and 7.45, and limited to a maximum of 35 breaths/min, $\mathrm{F}_{\mathrm{IO}_{2}}$ that kept arterial oxygen saturation at $88-95 \%$ or $\mathrm{P}_{\mathrm{aO}_{2}}$ at $55-80 \mathrm{~mm} \mathrm{Hg}$, and PEEP adjusted to achieve the best oxygenation with the lowest $\mathrm{F}_{\mathrm{IO}_{2}}$ while avoiding adverse hemodynamic effects. If the plateau pressure was $>30 \mathrm{~cm} \mathrm{H}_{2} \mathrm{O}$ with a $\mathrm{V}_{\mathrm{T}}$ of $6 \mathrm{~mL} /$ $\mathrm{kg}$ PBW, a stepwise $\mathrm{V}_{\mathrm{T}}$ reduction of $1 \mathrm{~mL} / \mathrm{kg}$ PBW to as low as $4 \mathrm{~mL} / \mathrm{kg} / \mathrm{PBW}$ was allowed, in which case the plateau pressure limit was set at $35 \mathrm{~cm} \mathrm{H}_{2} \mathrm{O}$.

After 24 hours, subjects who met the inclusion criteria were randomized to either $\mathrm{F}_{\mathrm{IO}_{2}}$-guided PEEP (control group) or compliance-guided PEEP. Randomization was performed in blocks of 10, using sealed envelopes.

In the control group, PEEP was set based on the subject's $\mathrm{F}_{\mathrm{IO}_{2}}$, as applied in the ARDS Network study. ${ }^{18}$ In the compliance-guided group, PEEP was set daily, according to the method described by Suter et al. ${ }^{12}$ Static compliance was measured at increasing levels of PEEP and at constant PEEP. Static compliance was calculated as $V_{T}$ divided by the pressure difference at end of inflation hold ( $2 \mathrm{~s})$, and PEEP was increased in steps of $2 \mathrm{~cm} \mathrm{H}_{2} \mathrm{O}$, beginning at $5 \mathrm{~cm} \mathrm{H}_{2} \mathrm{O}$, without an upper PEEP titration limit. The highest static compliance was considered to be the best PEEP. If at 2 different PEEPs the static compliance was 
identical, we chose the one with the lower plateau pressure (see the respiratory protocol in the supplementary materials at http://www.rcjournal.com). All subjects received sedatives and opioids at the time of PEEP setting. Neuromuscular blocking agents were used as required for low- $\mathrm{V}_{\mathrm{T}}$ ventilation, although not for the measurement of intrinsic PEEP or plateau pressure.

According to the study group, PEEP was adjusted once daily during the morning shift, until the weaning phase started. Intrinsic PEEP was measured before and after every change of applied PEEP, and the inspiratory/expiratory ratio was changed accordingly to prevent intrinsic PEEP.

All other ventilator parameters were set in the same way in both study groups, following the protocol applied for 24 hours before randomization. ${ }^{18}$

The weaning protocol was identical for both groups. Weaning was begun if the cause of respiratory failure had resolved, $\mathrm{P}_{\mathrm{aO}_{2}}$ was $>60 \mathrm{~mm} \mathrm{Hg}, \mathrm{F}_{\mathrm{IO}_{2}}$ was $\leq 0.4$, and PEEP was below $6 \mathrm{~cm} \mathrm{H}_{2} \mathrm{O}$. In the compliance-guided group, PEEP was lowered by steps of $2 \mathrm{~cm} \mathrm{H}_{2} \mathrm{O}$. In the control group we applied the protocol described in the ARDS Network study ${ }^{18}$ (see the supplementary materials at http://www.rcjournal.com).

Subjects were monitored with a pulmonary artery catheter for at least the first 72 hours after randomization, to study the hemodynamic effects of PEEP. Therapy other than mechanical ventilation was prescribed at the discretion of the attending physicians not involved in the study. Our local protocols were applied to guide sedation, hemodynamic support, and other standard interventions.

End points were assessed at 28 days. The primary end point was $\mathrm{P}_{\mathrm{OO}_{2}} / \mathrm{F}_{\mathrm{IO}_{2}}$. Secondary end points were mortality, ventilator-free days, ICU and hospital stay, multipleorgan-dysfunction (MOD) free days, and respiratory and hemodynamic parameters.

\section{Measurements}

Data collected from each subject included demographics, risk factors for ARDS, routine laboratory measurements, Acute Physiology and Chronic Health Evaluation II score $^{21}$ at ICU admission, daily Lung Injury Score, ${ }^{22}$ Sepsis-Related Organ Failure Assessment score, ${ }^{23}$ MOD score, ${ }^{24}$ days on mechanical ventilation, ICU and hospital outcomes and stay, 28-day mortality, pulmonary measurements, physiologic measurements, ventilatory measurements, cardiovascular measurements, adverse events, extrapulmonary organ failures, sedation, and daily chest $\mathrm{x}$-ray. All measurements and data were recorded at study inclusion, at 6 hours after inclusion, and between 6:00 AM and 8:00 AM on days $1,2,3,4,7,14,21$, and 28.

Organ failure was defined as a Sepsis-Related Organ Failure Assessment score ${ }^{23}>2$, and MOD requires $\geq 2$ organ failures. Organ-dysfunction-free days were de-

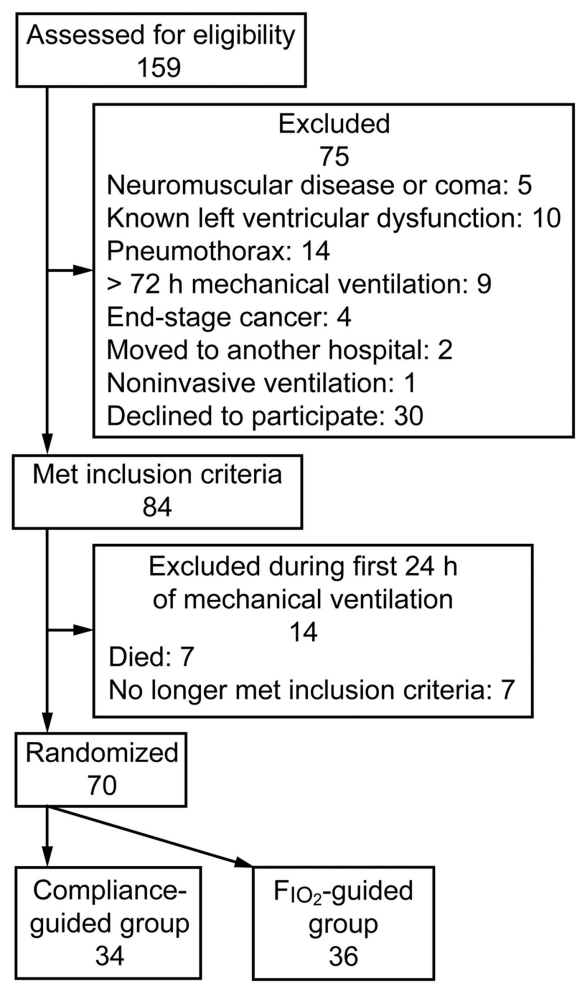

Fig. 1. Screening and enrollment.

fined as days alive and free of any organ dysfunction, ${ }^{15,17}$ and ventilator-free days were defined as days of unassisted breathing, both calculated at 28 days (all deaths occurring prior to day 28 were considered as zero organdysfunction-free or ventilator-free days). ${ }^{18}$ Subjects were followed until hospital discharge or death.

\section{Statistical Analysis}

Normality of data distribution was assessed using the Kolmogorov-Smirnov test. Quantitative variables with normal distribution are expressed as mean $\pm \mathrm{SD}$, and were compared using the Student $t$ test. Non-normal distribution variables are shown as medians and interquartile ranges, and were compared using the Mann-Whitney test. Qualitative variables are shown as percentages, and were compared with the chi-square test. Kaplan-Meier analysis with log-rank test was applied to compare survival at 28 days between groups. Statistical significance was set at $P<.05$, and results are expressed with their $95 \%$ confidence intervals. Statistical analysis was performed using statistics software (SPSS 15.0, SPSS, Chicago, Illinois).

\section{Results}

A total of 159 patients met the criteria for ARDS during the study period, 70 of whom were randomized to either 
Table 1. Baseline Characteristics of Subjects at Study Inclusion

\begin{tabular}{|c|c|c|}
\hline & $\begin{array}{c}\mathrm{F}_{\mathrm{IO}_{2}}-\text { Guided PEEP } \\
(n=36)\end{array}$ & $\begin{array}{l}\text { Compliance-Guided PEEP } \\
\qquad(n=34)\end{array}$ \\
\hline Male, no. $(\%)$ & $29(80.55)$ & $20(58.82)$ \\
\hline Age, y & $54.1 \pm 2.9$ & $55.6 \pm 3.1$ \\
\hline APACHE II score & $20.53 \pm 1.33$ & $18.71 \pm 1.02$ \\
\hline SOFA score & $8.86 \pm 0.61$ & $9.38 \pm 0.66$ \\
\hline Multiple-organ-dysfunction score & $8.36 \pm 0.52$ & $8.50 \pm 0.57$ \\
\hline Lung Injury Score, median (IQR) & $3(2.5-3.25)$ & $3(2.5-3.25)$ \\
\hline Percentage of patients with multiple-organ-dysfunction syndrome* & 77.8 & 97.1 \\
\hline $\mathrm{P}_{\mathrm{aO}_{2}} / \mathrm{F}_{\mathrm{IO}_{2}}, \mathrm{~mm} \mathrm{Hg}$ & $133.15 \pm 5.88$ & $146.33 \pm 6.19$ \\
\hline PEEP pre-randomization, median (IQR) $\mathrm{cm} \mathrm{H}_{2} \mathrm{O}$ & $10(8-14)$ & $10(8-12)$ \\
\hline Tidal volume, $\mathrm{mL} / \mathrm{kg}$ predicted body weight & $6.61 \pm 0.87$ & $6.66 \pm 1.01$ \\
\hline Peak pressure, $\mathrm{cm} \mathrm{H}_{2} \mathrm{O}$ & $38.10 \pm 1.11$ & $38.22 \pm 1.33$ \\
\hline Plateau pressure, $\mathrm{cm} \mathrm{H}_{2} \mathrm{O}$ & $31.87 \pm 1.56$ & $28.24 \pm 1.22$ \\
\hline Breathing frequency, breaths/min & $23 \pm 1$ & $25 \pm 1$ \\
\hline Minute ventilation, $\mathrm{L} / \mathrm{min}$ & $12.1 \pm 0.4$ & $12.9 \pm 0.4$ \\
\hline $\mathrm{pH}$ & $7.34 \pm 0.01$ & $7.33 \pm 0.01$ \\
\hline $\mathrm{P}_{\mathrm{aCO}_{2}}, \mathrm{~mm} \mathrm{Hg}$ & $43.28 \pm 1.27$ & $42.11 \pm 1.01$ \\
\hline \multicolumn{3}{|c|}{$\begin{array}{l}\text { Values are mean } \pm \mathrm{SD} \text { unless otherwise indicated. } \\
\text { * There were no significant differences between the groups at study randomization, except percentage of patients with multiple-organ-dysfunction syndrome: } P=.02 \text {. } \\
\text { APACHE = Acute Physiology and Chronic Health Evaluation } \\
\text { SOFA }=\text { sepsis-related organ failure assessment }\end{array}$} \\
\hline
\end{tabular}

compliance-guided $(n=34)$ or $\mathrm{F}_{\mathrm{IO}_{2}}$-guided PEEP adjustment $(n=36)$ (Fig. 1). No patients were excluded after randomization or discharged from hospital earlier than 28 days.

The main cause of ARDS was infection $(n=50,71.4 \%)$ (detailed causes of ARDS per study group are shown in the supplementary materials at http://www.rcjournal.com). There were no significant differences in subject characteristics between study groups at randomization, except for the high incidence of MOD in the compliance-guided group (Table 1).

\section{Physiological Measurements}

There was no difference in median PEEP at study entry (Fig. 2). Figure 3 shows the ventilatory parameters over the 28-day study period. There was no significant difference in $\mathrm{P}_{\mathrm{aO}_{2}} / \mathrm{F}_{\mathrm{IO}_{2}}$. There was a trend toward better oxygenation in the compliance-guided group over the first 2 weeks of study (see Fig. 3 and the supplementary materials at http://www.rcjournal.com). In the complianceguided group there was also a nonsignificantly higher pulmonary compliance and lower airway pressure (see Fig. 3 and the supplementary materials at http://www.rcjournal. com). There were no differences in $\mathrm{pH}, \mathrm{V}_{\mathrm{T}}$, intrinsic PEEP, or breathing frequency (see the supplementary materials at http://www.rcjournal.com).

In a post-hoc analysis we found that $80 \%$ of the subjects in the compliance-guided group would have had a differ-

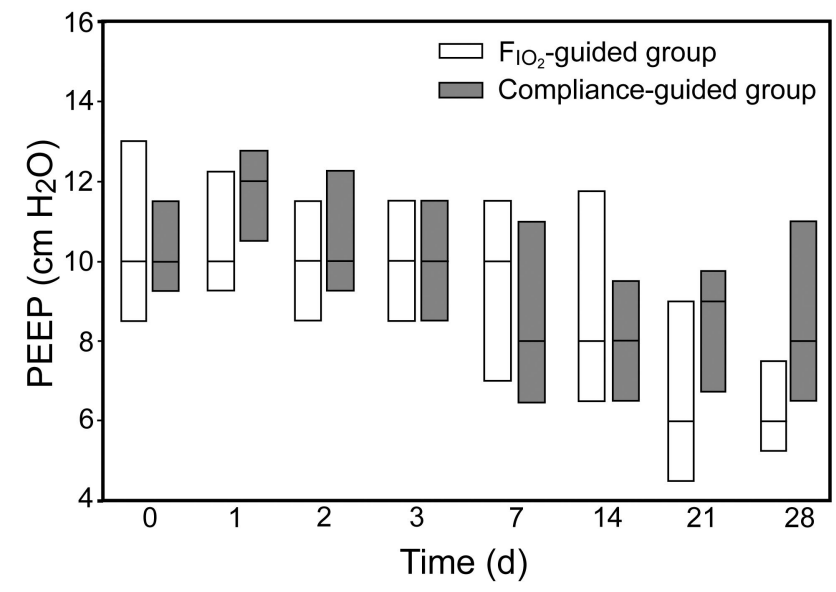

Fig. 2. PEEP in the first 28 days.

ent PEEP if set according to the $\mathrm{F}_{\mathrm{IO}_{2}}$ /PEEP table. There were no limitations in daily PEEP changes, rather than the measurement frequency of PEEP.

\section{Clinical Outcomes}

The compliance-guided group had significantly more MOD-free days at day 28 (Table 2), in spite of a higher baseline incidence (see Table 1), as well as more ventilator-free days and hemodynamic failure-free days.

Twelve subjects developed barotrauma after randomization: 6 per study group (see Table 2). A total of 9 episodes 

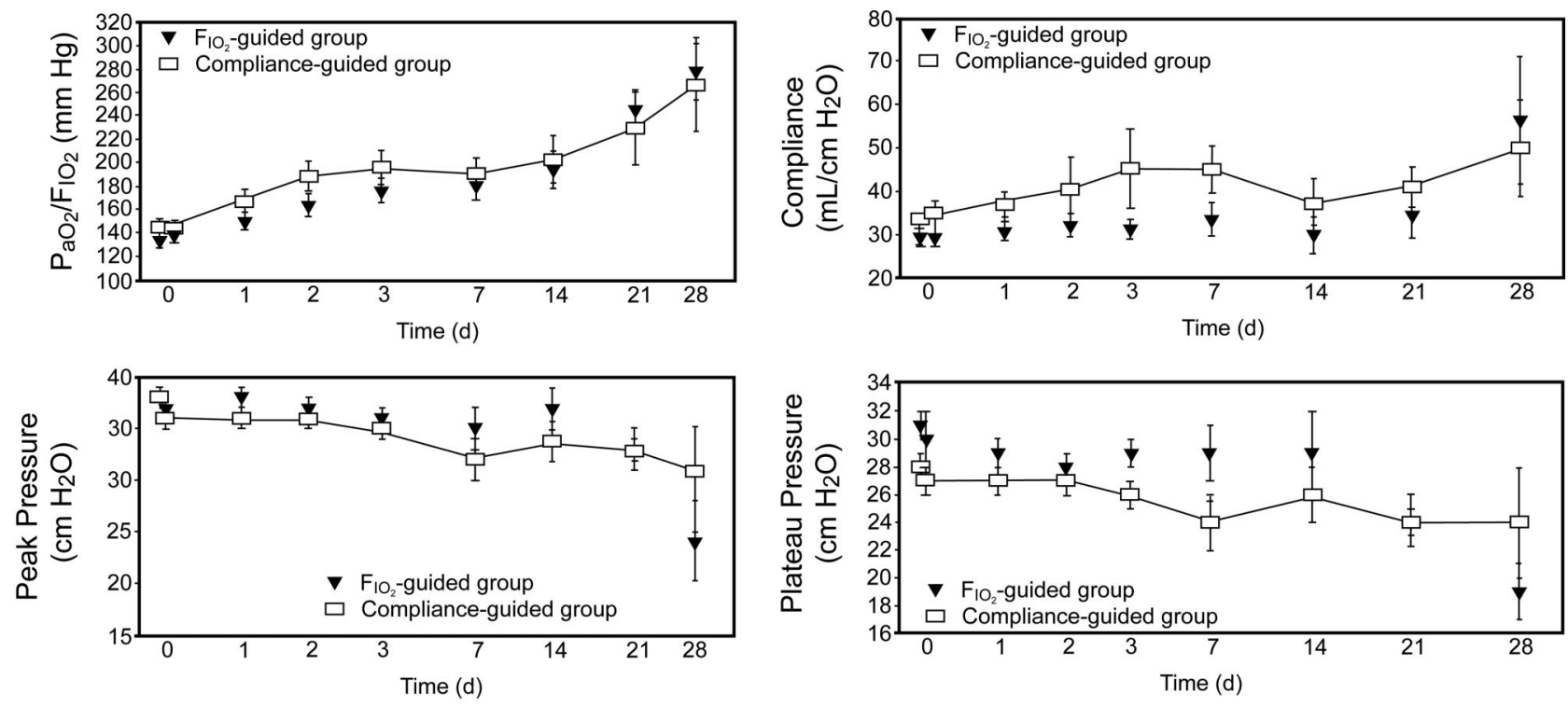

Fig. 3. $\mathrm{P}_{\mathrm{aO}_{2}} / \mathrm{F}_{\mathrm{IO}_{2}}$, static compliance, peak pressure, and plateau pressure.

Table 2. Clinical Outcomes

\begin{tabular}{|c|c|c|c|}
\hline & $\begin{array}{c}\mathrm{F}_{\mathrm{IO}_{2}}-\text { Guided PEEP } \\
(n=36)\end{array}$ & $\begin{array}{l}\text { Compliance-Guided PEEP } \\
\qquad(n=34)\end{array}$ & $P$ \\
\hline 28-day mortality, no. (\%) & $14(38.9)$ & $7(20.6)$ & .12 \\
\hline Multiple-organ-dysfunction-free days at 28 days & $6(0-23.75)$ & $20.5(0-26)$ & .02 \\
\hline Respiratory-failure-free days at 28 days & $7.5(0-19)$ & $14.5(0-22.5)$ & .03 \\
\hline Hemodynamic failure-free days at 28 days & $16(0-23.75)$ & $22(0-25)$ & .04 \\
\hline Renal-failure-free days at 28 days & $28(0-28)$ & $28(0-28)$ & .39 \\
\hline Hematological-failure-free days at 28 days & $25.5(0-28)$ & $28(0-28)$ & .52 \\
\hline Hepatic-failure-free days at 28 days & $28(0-28)$ & $28(0-28)$ & .08 \\
\hline ICU stay, d & $20(12-29)$ & $21(15-46)$ & .24 \\
\hline Hospital stay, mean $\pm \mathrm{SD} d$ & $32 \pm 3$ & $55 \pm 7$ & .01 \\
\hline ICU-free days at 28 days & $0(0-11)$ & $0(0-14)$ & .84 \\
\hline Ventilator-free days at 28 days & $0(0-15.75)$ & $1(0-18)$ & .16 \\
\hline Barotrauma, no. (\%) & $6(16.7)$ & $6(17.6)$ & .99 \\
\hline
\end{tabular}

Values are median (IQR) unless otherwise indicated.

of barotrauma occurred during the first week: 5 in the compliance-guided group, and 4 in the $\mathrm{F}_{\mathrm{IO}_{2}}$-guided group. One subject in the compliance-guided group and 2 in $\mathrm{F}_{\mathrm{IO}_{2}}{ }^{-}$ guided group developed barotrauma in the second week of study.

Global 28-day mortality was 30\% (21 subjects), with a hospital mortality of $42.8 \%$ ( 30 subjects). 28-day mortality was $20.6 \%(n=7)$ in the compliance-guided group and $38.9 \%(n=14)$ in the $\mathrm{F}_{\mathrm{IO}_{2}}$-guided group $(P=.12)$ (Fig. 4). The main causes of death were multi-organ failure $(n=50$, $71.4 \%)$ and refractory hypoxemia $(n=10,14.3 \%)$. Subjects who died had a higher Sepsis-Related Organ Failure Assessment score ${ }^{23}$ at inclusion (11.4 \pm 0.7 vs $8.1 \pm 0.5$, $P=.01)$, as well as lower $\mathrm{P}_{\mathrm{aO}_{2}} / \mathrm{F}_{\mathrm{IO}_{2}}(126.4 \pm 9.6 \mathrm{~mm} \mathrm{Hg}$ vs $145.1 \pm 4.3 \mathrm{~mm} \mathrm{Hg}, P=.04)$ and a higher Lung Injury $\operatorname{Score}^{22}(3.25[2.50-3.50]$ vs 3.00 [2.50-3.25], $P=.04)$.

There were no significant differences in hemodynamic variables or sedative dosage between the groups (see the supplementary materials at http://www.rcjournal.com). There were no complications associated with insertion of the pulmonary artery catheter.

\section{Discussion}

In subjects with ARDS, ventilated with low $\mathrm{V}_{\mathrm{T}}$ and airway pressure limited to $30 \mathrm{~cm} \mathrm{H}_{2} \mathrm{O}$, compliance-guided PEEP adjustment, compared to $\mathrm{F}_{\mathrm{IO}_{2}}$-guided PEEP adjustment, had no significant effect on oxygenation, although it 


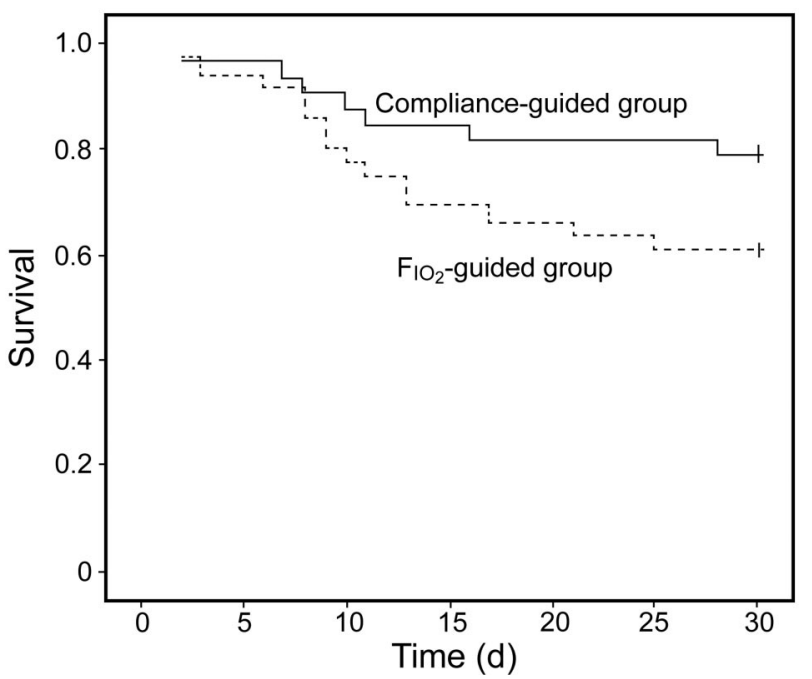

Fig. 4. Kaplan-Meier curves for survival.

was associated with a significant reduction of the duration of MOD.

To our knowledge, static-compliance-guided PEEP has not previously been studied in a large group of subjects under lung-protective ventilation. ${ }^{25}$ Interestingly, there was no significant difference in the mean PEEP applied to the 2 groups. In previous studies PEEP was higher if set according to "compliance." $13,17,26$ Although mean PEEP was similar, our post-hoc analysis showed that $80 \%$ of the compliance-guided subjects would have received different PEEP than did the control group. Hypothetically, subjects with customized PEEP might have been on higher or lower PEEP than those prescribed PEEP according to the $\mathrm{PEEP} / \mathrm{F}_{\mathrm{IO}_{2}}$ table. Thus, the similar mean PEEP value, in our opinion, does not exclude the possibility that individual compliance-guided PEEP might be distributed over a wider range and might be associated with less ventilatorinduced lung injury.

We also found that subjects on compliance-guided PEEP had nonsignificantly lower plateau pressures over the first 21 days of study (see Fig. 3). This could be explained by improved alveolar recruitment, since other respiratory parameters were set according to the same protocol in both groups, but this needs to be confirmed in a larger study. In previous studies, lower plateau pressure has been associated with lower mortality, ${ }^{18}$ and, similar to our findings, shorter duration of MOD. ${ }^{17,18}$

There have been only 3 randomized controlled clinical trials in which PEEP set according to the pressurevolume curve was compared with other methods of setting PEEP. ${ }^{13-15}$ Those studies compared higher versus lower $\mathrm{V}_{\mathrm{T}}$ and found progressive improvement of oxygenation ${ }^{14}$ over the first week. ${ }^{13,15}$ There were no data about the course of oxygenation beyond the first week. Those studies differed from ours in that PEEP was set slightly above the lower inflection point of the quasi-static pressurevolume curve. That method correlates poorly with alveolar recruitment, and therefore with total alveolar compliance. ${ }^{27}$ We also found a nonsignificant improvement in oxygenation in the compliance-guided group during the first 2 weeks, but this effect was not observed at later stages. Unlike in previous studies, improved oxygenation, if confirmed, may be attributed to the method of PEEP determination, since this was the only difference between the 2 study groups. Comparisons of oxygenation data are methodologically very difficult because of important differences in clinical course and how death and weaning should statistically be accounted for. In addition, in later stages of ARDS, with increased lung fibrosis, ${ }^{28,29}$ the use of the pressure-volume curve may be less effective in achieving alveolar recruitment and, consequently, in improving oxygenation.

We observed that customizing PEEP to the individual subject was associated with shorter duration of MOD at 28 days. It is reasonable to assume that this effect is the cause for the strong trend toward lower mortality in this study group. Previous studies have been criticized for similar results because subjects were ventilated with high $\mathrm{V}_{\mathrm{T}}$, which is associated with higher mortality. ${ }^{18} \mathrm{~A}$ metaanalysis $^{30}$ of 3 studies ${ }^{13-15}$ showed significantly lower mortality if PEEP was determined according to the pressurevolume curve. This effect on duration of MOD may be related to a reduced release of inflammatory cytokines. Several clinical studies have confirmed that an array of inflammatory cytokines is released into the systemic circulation as a consequence of high $\mathrm{V}_{\mathrm{T}}$ or high PEEP, which correlates with higher morbidity and mortality. ${ }^{14,18,31,32}$

Other studies have compared methods of setting PEEP. The Express study ${ }^{17}$ showed that, compared to a fixed and low PEEP, an individualized PEEP set at the highest value allowing a plateau pressure of $28-30 \mathrm{~cm} \mathrm{H}_{2} \mathrm{O}$ is associated with significant increase of MOD-free days at 28 days, without improving survival. Talmor et $\mathrm{al}^{26}$ compared the application of fixed PEEP according to the ARDS Network standard-of-care recommendations, ${ }^{18}$ with an individualized method based on transpulmonary pressure at end-expiration. They found improved oxygenation, as well as a trend toward lower mortality in the customized PEEP group. It is interesting to note that, as in our study, Talmor et al found that the respiratory-system compliance appeared to be higher in their esophageal-pressure-guided group. ${ }^{26}$ Unlike in our study, however, they determined PEEP decrementally after a recruitment maneuver, which has been demonstrated to influence the evaluation of lung compliance according to the pressure-volume curve. ${ }^{27,33}$

Grasso et $\mathrm{al}^{34}$ found that, compared to the ARDS Network protocol, ${ }^{18}$ in subjects with a focal pattern of loss of aeration, PEEP is lower if set according to stress index and that the application of the ARDS Network protocol ${ }^{18}$ in- 


\section{Individualized PEEP Setting in SubJects With ARDS}

duces alveolar hyperinsufflation and increases cytokine plasma levels. The LOVs ${ }^{16}$ study found a lower incidence of refractory hypoxemia and need for rescue therapies associated with the application of PEEP according to $\mathrm{F}_{\mathrm{IO}_{2}}$ after a 40-second, $40 \mathrm{~cm} \mathrm{H}_{2} \mathrm{O}$ airway pressure recruitment maneuver, compared to the ARDS Network protocol ${ }^{18}$ without previous recruitment maneuver, although without a statistically significant difference in rates of all-cause hospital mortality or barotrauma.

In our study 12 subjects (17\%) developed barotrauma. The incidence of barotrauma in ARDS has been reported to range between 0 and $>76 \%, 35$ although recent studies show reduced incidences between $6 \%$ and 10\%.16,17,36,37 Risk factors for barotrauma included high peak airway pressure, large $\mathrm{V}_{\mathrm{T}}$, and the level of acute lung injury. ${ }^{38}$ The slightly higher incidence of barotrauma in our study may be explained by the high Lung Injury Score, ${ }^{22}$ as large $\mathrm{V}_{\mathrm{T}}$ and high peak airway pressure were avoided. The incidence of barotrauma was similar in our 2 study groups. Previous studies have not found differences in the incidence of barotrauma according the different levels or methods of PEEP applied. 16,17,36,37

Our study has several limitations. Being a pilot study with the aim to provide a basis for a future multicenter study, it had a small sample size and its results require confirmation. The study was carried out in a single center, and included only $44 \%$ of subjects who met the inclusion criteria. Although randomized, the study was unblinded, and bias cannot be excluded. Some difficulties in setting PEEP at best compliance became apparent during the study. At times, several time-consuming attempts were required to find the best PEEP in the compliance group, including the need for muscle relaxants, or the study procedures had to be interrupted to allow for endotracheal suctioning. We also did not measure inflammatory cytokines to support the findings on MOD.

\section{Conclusions}

In conclusion, this randomized controlled pilot trial showed that individualized PEEP selection based on the best static compliance in subjects with ARDS treated with low $\mathrm{V}_{\mathrm{T}}$ and limited plateau pressure did not improve oxygenation, but was associated with a significant increase in organ-dysfunction-free days and a strong trend toward lower mortality at day 28. Larger, randomized, multicenter trials are necessary to validate this approach as an integral part of lung-protective strategy.

\section{REFERENCES}

1. Bernard GR, Artigas A, Brigham KL, Carlet J, Falke K, Hudson L, et al. The American-European Consensus Conference on ARDS. Definitions, mechanisms, relevant outcomes, and clinical trial coordination. Am J Respir Crit Care Med 1994;149(3 Pt 1):818-824.
2. Diaz JV, Brower R, Calfee CS, Matthay MA. Therapeutic strategies for severe acute lung injury. Crit Care Med 2010;38(8): 1644-1650.

3. Gattinoni L, Protti A, Caironi P, Carlesso E. Ventilator-induced lung injury: the anatomical and physiological framework. Crit Care Med 2010;38(10 Suppl):S539-S548.

4. Pipeling MR, Fan E. Therapies for refractory hypoxemia in acute respiratory distress syndrome. JAMA 2010;304(22):2521-2527.

5 . Villar J. The use of positive end-expiratory pressure in the management of the acute respiratory distress syndrome. Minerva Anestesiol 2005;71(6):265-272.

6. Marini JJ. Initial management of acute hypoxemia. In: Shoemaker WC, Ayres SM, Grenvik A, Holbrook PR, eds. Textbook of Critical Care, $4^{\text {th }}$ ed. Philadelphia: WB Saunders; 2000:1412.

7. Dellinger RP, Levy MM, Carlet JM, Bion J, Parker MM, Jaeschke R, et al. Surviving Sepsis Campaign: international guidelines for management of severe sepsis and septic shock: 2008. Crit Care Med 2008;36(1):296-327.

8. Gattinoni L, Caironi P. Refining ventilatory treatment for acute lung injury and acute respiratory distress syndrome. JAMA 2008;299(6): 691-693.

9. Gattinoni L, Caironi P, Cressoni M, Chiumello D, Ranieri VM, Quintel M, et al. Lung recruitment in patients with the acute respiratory distress syndrome. N Engl J Med 2006;354(17): 1775-1786.

10. Gattinoni L, Carlesso E, Brazzi L, Caironi P. Positive end-expiratory pressure. Curr Opin Crit Care 2010;16(1):39-44.

11. Rouby JJ, Lu Q, Goldstein I. Selecting the right level of positive end-expiratory pressure in patients with acute respiratory distress syndrome. Am J Respir Crit Care Med 2002;165(8):1182-1186.

12. Suter PM, Fairley HB, Isenberg MD. Effect of tidal volume and positive end-expiratory pressure on compliance during mechanical ventilation. Chest 1978;73(2):158-162.

13. Amato MB, Barbas CS, Medeiros DM, Magaldi RB, Schettino GP, Lorenzi-Filho G, et al. Effect of a protective-ventilation strategy on mortality in the acute respiratory distress syndrome. N Engl J Med 1998;338(6):347-354.

14. Ranieri VM, Suter PM, Tortorella C, De Tullio R, Dayer JM, Brienza A, et al. Effect of mechanical ventilation on inflammatory mediators in patients with acute respiratory distress syndrome: a randomized controlled trial. JAMA 1999;282(1):54-61.

15. Villar J, Kacmarek RM, Pérez-Méndez L, Aguirre-Jaime A. A high positive end-expiratory pressure, low tidal volume ventilatory strategy improves outcomes in persistent acute respiratory distress syndrome: a randomized, controlled trial. Crit Care Med 2006;34(5): 1311-1318.

16. Meade MO, Cook DJ, Guyatt GH, Slutsky AS, Arabi YM, Cooper DJ, et al; Lung Open Ventilation Study Investigators. Ventilation strategy using low tidal volumes, recruitment maneuvers, and high positive end-expiratory pressure for acute lung injury and acute respiratory distress syndrome: a randomized controlled trial. JAMA 2008;299(6):637-645.

17. Mercat A, Richard JC, Vielle B, Jaber S, Osman D, Diehl JL, et al; Expiratory Pressure (Express) Study Group. Positive end-expiratory pressure setting in adults with acute lung injury and acute respiratory distress syndrome: a randomized controlled trial. JAMA 2008;299(6): 646-655.

18. The Acute Respiratory Distress Syndrome Network. Ventilation with lower tidal volumes as compared with traditional tidal volumes for acute lung injury and the acute respiratory distress syndrome. N Engl J Med 2000;342(18):1301-1308.

19. Ferguson ND, Kacmarek RM, Chiche JD, Singh JM, Hallett DC, Mehta S, et al. Screening of ARDS patients using standardized ven- 


\section{Individualized PEEP Setting In SubJects With ARDS}

tilator settings: influence on enrollment in a clinical trial. Intensive Care Med 2004;30(6):1111-1116.

20. Weg JG, Anzueto A, Balk RA, Wiedemann HP, Pattishall EN, Schork MA, et al. The relation of pneumothorax and other air leaks to mortality in the acute respiratory distress syndrome. N Engl J Med 1998;338(6):341-346.

21. Knaus WA, Draper EA, Wagner DP, Zimmerman JE. APACHE II: a severity of disease classification system. Crit Care Med 1985; 13(10):818-829.

22. Murray JF, Matthay MA, Luce JM, Flick MR. An expanded definition of the adult respiratory distress syndrome. Am Rev Respir Dis 1988;138(3):720-723.

23. Vincent JL, de Mendonca A, Cantraine F, Moreno R, Takala J, Suter PM, et al. Use of the SOFA score to assess the incidence of organ dysfunction/failure in intensive care units: results of a multicenter, prospective study. Working Group on Sepsis-Related Problems of the European Society of Intensive Care Medicine. Crit Care Med 1998;26(11):1793-1800.

24. Marshall JC, Cook DJ, Christou NV, Bernard GR, Sprung CL, Sibbald WJ. Multiple organ dysfunction score: a reliable descriptor of a complex clinical outcome. Crit Care Med 1995;23(10):1638-1652.

25. Amato MB, Barbas CS, Medeiros DM, Schettino GP, Lorenzi FG, Kairalla RA, et al. Beneficial effects of the "open lung approach" with low distending pressures in acute respiratory distress syndrome. A prospective randomized study on mechanical ventilation. Am J Respir Crit Care Med 1995;152(6 Pt 1):1835-1846.

26. Talmor D, Sarge T, Malhotra A, O'Donnell CR, Ritz R, Lisbon A, et al. Mechanical ventilation guided by esophageal pressure in acute lung injury. N Engl J Med 2008;359(20):2095-2104.

27. Hickling, KG. Best compliance during a decremental, but not incremental, positive end-expiratory pressure trials is related to open-lung positive end-expiratory pressure. Am J Respir Crit Care Med 2001; 163(1):69-78.

28. Grasso S, Mascia L, Del Turco M, Malacarne P, Giunta F, Brochard $\mathrm{L}$, et al. Effects of recruiting maneuvers in patients with acute respiratory distress syndrome ventilated with protective ventilatory strategy. Anesthesiology 2002;96(4):795-802.
29. Ware LB. Pathophysiology of acute lung injury and the acute respiratory distress syndrome. Semin Respir Crit Care Med 2006;27(4): 337-349.

30. Gordo-Vidal F, Gómez-Tello V, Palencia-Herrejón E, Latour-Pérez J, Sánchez-Artola B, Díaz-Alersi R. [High PEEP vs conventional PEEP in the acute respiratory distress syndrome: a systematic review and meta-analysis]. Med Intensiva 2007;31(9):491-501. Article in Spanish.

31. Parsons PE, Matthay MA, Ware LB, Eisner MD. Elevated plasma levels of soluble TNF receptors are associated with morbidity and mortality in patients with acute lung injury. Am J Physiol Lung Cell Mol Physiol 2005;288(3):L426-L431.

32. Parsons PE, Eisner MD, Thompson BT, Matthay MA, Ancukiewicz M, Bernard GR, et al. Lower tidal volume ventilation and plasma cytokine markers of inflammation in patients with acute lung injury. Crit Care Med 2005;33(1):1-6.

33. Suarez-Sipmann F, Bohm SH. Recruit the lung before titrating the right positive end-expiratory pressure to protect it. Crit Care 2009; 13(3):134.

34. Grasso S, Stripoli T, De Michele M, Bruno F, Moschetta M, Angelelli G, et al. ARDSnet ventilatory protocol and alveolar hyperinflation: role of positive end-expiratory pressure. Am J Respir Crit Care Med 2007;176(8):761-767.

35. Boussarsar M, Thierry G, Jaber S, Roudot-Thoraval F, Lemaire F, Brochard L. Relationship between ventilatory settings and barotrauma in the acute respiratory distress syndrome. Intensive Care Med 2002; 28(4):406-413

36. Briel M, Meade M, Mercat A, Brower RG, Talmor D, Walter SD, et al. Higher vs lower positive end-expiratory pressure in patients with acute lung injury and acute respiratory distress syndrome: systematic review and meta-analysis. JAMA 2010;303(9):865-873.

37. Brower RG, Lanken PN, MacIntyre NR, Matthay MA, Morris A, Ancukiewicz M, et al. Higher versus lower positive end-expiratory pressures in patients with the acute respiratory distress syndrome. N Engl J Med 2004;351(4):327-336.

38. Meade MO, Cook DJ. The aetiology, consequences and prevention of barotrauma: a critical review of the literature. Clin Intensive Care 1995;6(4):166-173.

This article is approved for Continuing Respiratory Care Education credit. For information and to obtain your CRCE

(free to AARC members) visit

www.rcjournal.com

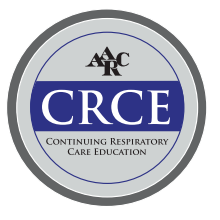

